results were essentially unchanged. Finally, it should be emphasised that our study was carried out in developing countries and its findings may therefore not be applicable to other populations.

The risks for maternal perinatal morbidity and mortality associated with short interpregnancy intervals underscore the importance of birth spacing by using the available methods of family planning, particularly after a birth, to promote safe motherhood and achieve better pregnancy outcomes. In addition, women should be advised of the potential harm to them and their infants of short and long intervals between pregnancies.

We thank Mr Roberto Porro and Dr Felipe Santana for the preparation of the database. We also thank health workers and health related workers in many settings of the Latin American and Caribbean region for their efforts to collect and send Perinatal Information System data to the Latin American Centre for Perinatology and Human Development.

Contributors: AC-A originated and designed the study, analysed the data, and was mainly responsible for writing the paper; he will act as guarantor of the paper. JMB participated in the discussion of the study hypothesis and study design, contributed to the analyses, and helped to write the paper.

Funding: Division of Health Promotion and Protection, Pan American Health Organisation.

Competing interests: None declared.

1 Rawlings JS, Rawlings VB, Read JA. Prevalence of low birth weight and preterm delivery in relation to the interval between pregnancies among white and black women. N Engl J Med 1995;332:69-74.

2 Klerman LV, Cliver SP, Goldenberg RL. The impact of short interpregnancy intervals on pregnancy outcomes in a low-income population. Am J Public Health 1998;88:1182-5.

3 Khoshnood B, Lee KS, Wall S, Hsieh HL, Mittendorf R. Short interpregnancy intervals and the risk of adverse birth outcomes among five racial/ ethnic groups in the United States. Am J Epidemiol 1998;148:798-805.

4 Zhu BP, Rolfs RT, Nangle BE, Horan JM. Effect of the interval between pregnancies on perinatal outcomes. N Engl J Med 1999;340:589-94

5 Shults RA, Arndt V, Olshan AF, Martin CF, Royce RA. Effects of short interpregnancy intervals on small-for-gestational age and preterm births. Epidemiology 1999;10:250-4.

6 Eastman NJ. The effect of the interval between births on maternal and fetal outlook. Am J Obstet Gynecol 1944;47:445-66.

7 Anandalakshmy PN, Talwar PB, Buckshee K, Hingorani V. Demographic, socio-economic and medical factors affecting maternal mortality-an Indian experience. J Fam Welfare 1993;39:1-4

8 Lazovic N, Pocekovac P. The importance of time intervals between childbirth and anemia in pregnancy. Srp Arh Celok Lek 1996;124:307-10. (In Serbo-Croatian.)

9 Ronsmans C, Campbell O. Short birth intervals don't kill women: evidence from Matlab, Bangladesh. Stud Fam Plann 1998;29:282-90.

10 Schwarcz R, Diaz AG, Fescina R, Diaz JL, Martell M, Simini F. The perinatal information system. I: The simplified perinatal clinical record. J Perinat Med 1987;15(suppl 1):9.

\section{What is already known on this topic?}

Both short and long intervals between pregnancies are associated with adverse perinatal outcomes

Conflicting data exist on the impact of interpregnancy interval on maternal morbidity and mortality

\section{What does this study add?}

Women with interpregnancy intervals shorter than 6 months are at increased risk of maternal death, third trimester bleeding, premature rupture of membranes, puerperal endometritis, and anaemia

Women with interpregnancy intervals longer than 59 months are at increased risk of pre-eclampsia and eclampsia

As the research was carried out in developing countries the results may not apply to other populations

11 Diaz-Rosello JL. Health services research, outcomes, and perinatal information systems. Curr Opin Pediatr 1998;10:117-22.

12 Simini F. Perinatal information system (SIP): a clinical database in Latin America and the Caribbean. Lancet 1999;354:75.

13 Institute of Medicine, National Academy of Sciences. Nutrition during pregnancy and lactation. An implementation guide. Washington, DC: National Academy Press, 1992.

14 Mahfouz AA, el-Said MM, Alakija W, Badawi IA, al-Erian RA, Moneim MA. Anemia among pregnant women in the Asir region, Saudi Arabia: an epidemiologic study. Southeast Asian J Trop Med Public Health 1994;25:84-7.

15 Ananth CV, Wilcox AJ, Savitz DA, Bowes WA Jr, Luther ER. Effect of maternal age and parity on the risk of uteroplacental bleeding disorders in pregnancy. Obstet Gynecol 1996;88:511-6.

16 Miller JE. Birth intervals and perinatal health: an investigation of three hypotheses. Fam Plann Perspect 1991;23:62-70.

17 Winkvist A, Rasmussen KM, Habicht JP. A new definition of maternal depletion syndrome. Am J Public Health 1992;82:691-4.

18 Khan KS, Chien PF, Khan NB. Nutritional stress of reproduction. Acta Obstet Gynecol Scand 1998;77:395-401.

19 Alger LS, Pupkin MJ. Etiology of preterm premature rupture of the membranes. Clin Obstet Gynecol 1986;29:758-70.

20 Libombo A, Folgosa E, Bergstrom S. Risk factors in puerperal endometritis-myometritis. An incident case-referent study. Gynecol Obstet Invest 1994:38:198-205.

21 Naeye RL. Maternal age, obstetric complications, and the outcome of pregnancy. Obstet Gynecol 1983;61:210-6.

22 Trupin LS, Simon LP, Eskenazi B. Change in paternity: a risk factor for preeclampsia in multiparas. Epidemiology 1996;7:240-4.

23 Cobo E. Aplicación de un modelo de historia clínica perinatal. Rev Col Obstet Ginecol 1985;36:79-94.

(Accepted 11 September 2000)

\title{
The timing of the "fertile window" in the menstrual cycle: day specific estimates from a prospective study
}

\author{
Allen J Wilcox, David Dunson, Donna Day Baird
}

\author{
Abstract \\ Objectives To provide specific estimates of the likely \\ occurrence of the six fertile days (the "fertile window") \\ during the menstrual cycle. \\ Design Prospective cohort study. \\ Participants 221 healthy women who were planning \\ a pregnancy. \\ Main outcome measures The timing of ovulation in \\ 696 menstrual cycles, estimated using urinary \\ metabolites of oestrogen and progesterone. \\ Results The fertile window occurred during a broad \\ range of days in the menstrual cycle. On every day
}

between days 6 and 21, women had at minimum a $10 \%$ probability of being in their fertile window. Women cannot predict a sporadic late ovulation; $4-6 \%$ of women whose cycles had not yet resumed were potentially fertile in the fifth week of their cycle. Conclusions In only about $30 \%$ of women is the fertile window entirely within the days of the menstrual cycle identified by clinical guidelines-that is, between days 10 and 17. Most women reach their fertile window earlier and others much later. Women should be advised that the timing of their fertile window can be highly unpredictable, even if their cycles are usually regular. 
Biostatistics Branch, National Institute of Environmental Health Sciences David Dunson investigator

Correspondence to: A J Wilcox wilcox@niehs. nih.gov

\section{Introduction}

During the average woman's menstrual cycle there are six days when intercourse can result in pregnancy; this "fertile window" comprises the five days before ovulation and the day of ovulation itself. ${ }^{1-3}$ Just as the day of ovulation varies from cycle to cycle so does the timing of the six fertile days. Reliable methods to predict ovulation are lacking, therefore predicting the fertile window is also unreliable. Clinical guidelines suggest the cycle days during which the fertile window is most likely to occur, but these guidelines are outdated. We provide new estimates based on a prospective study of healthy women.

\section{Participants and methods}

Our data were drawn from a study of early pregnancy conducted in North Carolina. ${ }^{4}$ Overall, 221 women were enrolled at the time they discontinued their method of birth control. The protocol was approved by our institute's review board, and participants provided informed consent. We excluded women with known fertility problems. Most volunteers were white women aged between 25 and 35 and educated to college level; two thirds were nulliparous. At enrolment the women were asked about the regularity of their cycles and the usual length of their cycles. The participants collected the first urine sample of the morning each day and recorded the days during which intercourse and menstrual bleeding occurred. During the study, 136 women $(62 \%)$ conceived pregnancies that ended in live births. Details of study methods, participants, and pregnancy outcomes have been published. ${ }^{145}$

Day of ovulation was estimated from the changing ratio of urinary concentrations of oestrone-3glucuronide (a major metabolite of oestradiol) and pregnanediol-3-glucuronide (the major metabolite of progesterone), measured in daily urine specimens. ${ }^{67}$ Although no marker of ovulation corresponds perfectly with release of the egg, ${ }^{8}$ the steroid ratio based on the first urine sample of the morning seems to be as statistically precise in identifying ovulation as the surge in luteinising hormone concentration, either in urine or serum. ${ }^{9} 10$

The day of ovulation is the benchmark defining the six potentially fertile days of the menstrual cycle-that is, the five days before ovulation and ovulation itself. This fertile window was estimated from the present study, confirmed in a reanalysis of British data, and reported as a preliminary finding from a multicentre European study. ${ }^{1}, 311$

\section{Statistical analysis}

Day 1 of the menstrual cycle was defined by the onset of menstrual bleeding. The hormone algorithm estimated a day of ovulation for 696 cycles from 213 women. Each woman's cycles were weighted by the reciprocal of her number of cycles to avoid overrepresenting less fertile women who contributed more cycles. The frequency distribution of ovulation days was smoothed by fitting a $\log t$ distribution with a zero probability of ovulation on the first three days of the cycle.

The smoothed distribution of ovulation days provides an estimate of the probability that a woman ovulates on a particular day. The distribution also provides the probability that a particular day of the cycle falls within the fertile window. The day specific probabilities of being within the fertile window were calculated for all the women, for subgroups according to whether the women had reported their cycles to be regular or irregular, and for those women with regular cycles stratified by usual cycle length. The probability for a specific day applies only to women who have reached that day of their cycle-that is, women whose menses have not yet resumed.

This analysis assumes that the inherent fertility of a cycle is not related to the day of ovulation. We tested this assumption as follows. The rate of clinical pregnancy per cycle was $21 \%$ among all 696 cycles. This rate was 20\% among cycles with early ovulation (99 cycles before day 13) and 22\% among cycles with late ovulation (113 cycles after day 21). This apparent lack of association had also been found in earlier analyses of these data. ${ }^{12}$

\section{Results}

Ovulation occurred as early as the eighth day and as late as the 60th day of the menstrual cycle. Figure 1 shows the distribution of fertile days, generated by the smoothed distribution of ovulation days. Overall, an estimated $2 \%$ of women were in their fertile window by the fourth day of their cycle and $17 \%$ by the seventh day (based on 213 women). This percentage peaked on days 12 and 13, when 54\% of women were in their fertile window. If ovulation was delayed, women reached their fertile days much later. Among women who reached the fifth week of their cycle, $4-6 \%$ were in their fertile window.

At enrolment, $16 \%$ of women had reported that their cycles were "irregular" (the length of time

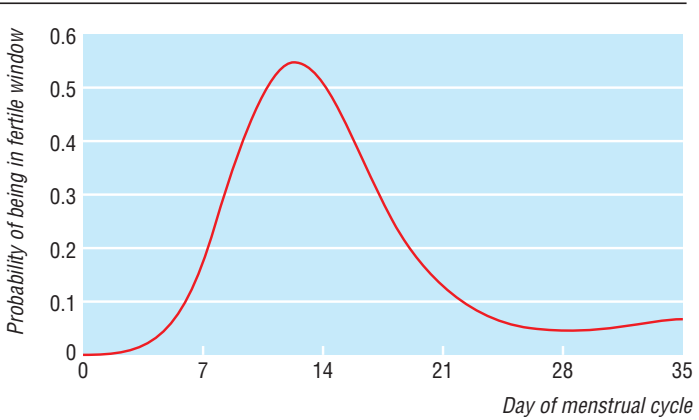

Fig 1 Probability of being in fertile window by day of menstrual cycle

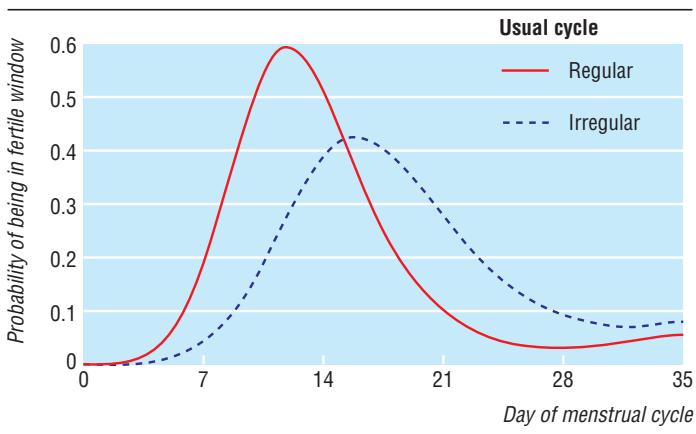

Fig 2 Probability of women with regular or irregular cycles being in their fertile window 


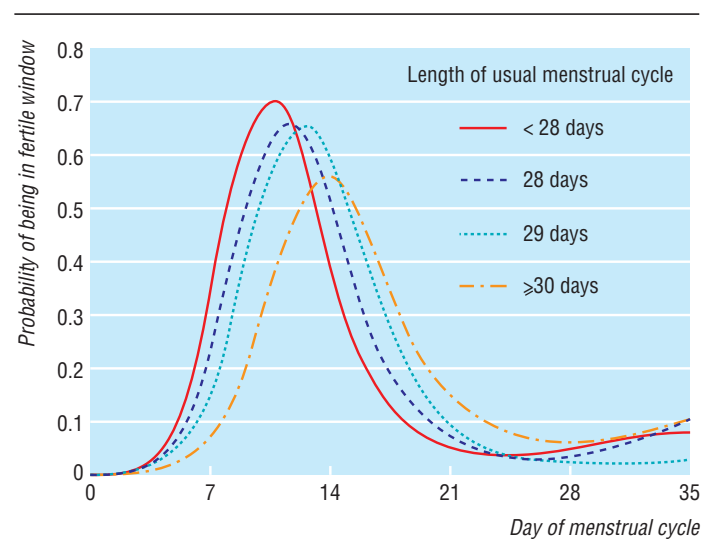

Fig 3 Probability of women with regular cycles being in fertile window, stratified by usual cycle length

between their periods was not generally the same from cycle to cycle). During the study, these women tended to ovulate later and at more variable times, resulting in their fertile days being spread more broadly across their cycles (fig 2).

The precision of the estimates can be improved by using women's reports of the usual length of their cycle. The women reported usual cycle lengths as short as 19 days and as long as 60 days, with 28 days being the most common. We found substantial correlation between usual cycle length at enrolment and day of ovulation (follicular phase length) during the study ( $\mathrm{R}=0.55$, all cycles). Thus, self reported cycle length can be useful in predicting whether a woman is in her fertile window.

Figure 3 shows the probability of women with regular cycles being in their fertile window, grouped by usual cycle length. Women who reported that their cycles usually lasted 27 days or less on average ovulated earlier during the study and therefore had earlier fertile windows than women with longer cycles. An estimated one third of the 39 women with short cycles had reached their fertile window by the end of the first week, compared with only $7 \%$ of the 55 women with long cycles (fig 3).

\section{Discussion}

During the first world war, a German doctor described 25 pregnancies that had resulted from single acts of intercourse with soldiers on military leave. ${ }^{13}$ The days on which conception occurred ranged from days 2 to 30 of the menstrual cycle. We know of no more recent empirical data on the range of fertile days in the menstrual cycle.

We estimated that women had a less than $1 \%$ probability of being within their fertile days (the "fertile window") by the second day of the menstrual cycle (fig 1). This probability, however, rose rapidly during the second week, and by days 12 and 13 just over half of the women were within their fertile days. Although late ovulation did not occur often, it was observed in all the subgroups. Even women who regarded their cycles as regular had a 1-6\% probability of being in their fertile window on the day their next menses was expected (fig 3).

\section{Biological interpretation}

Intercourse during the fertile window is not sufficient to produce pregnancy. Pregnancy depends on the viability of the sperm and egg, the receptivity of the uterus, and other factors that vary widely among couples. ${ }^{3}{ }^{12}$ Within the six fertile days of each cycle, the probability of conception is lowest on the first day. ${ }^{2}$ This is most relevant for the earliest days in the menstrual cycle, which are also the most likely to be the earliest (and least fertile) day of the fertile window.

Early ovulation has sometimes been thought to signal a less fertile cycle. For example, some authorities state that a cycle is seldom fertile when ovulation occurs before day 13 of the menstrual cycle. ${ }^{14}$ We found no evidence of this. Indeed, the earliest ovulation in our study (cycle day 8) produced a healthy infant.

\section{Clinical guidelines}

Current clinical guidelines about a woman's potentially fertile days have been based on two assumptions - that ovulation occurs 14 days before the next menses and that women are fertile for several days before and after ovulation. ${ }^{15}$ It follows that in the usual menstrual cycle lasting 28 days, the fertile days would fall between days 10 and $17 .{ }^{15}$ The assumptions are, however, outdated. Firstly, only a small percentage of women ovulate exactly 14 days before the onset of menses. ${ }^{10}{ }^{16}$ This is true even for women whose cycles are usually 28 days long. Among the 69 cycles for 28 days in our study, ovulation occurred 14 days before the next menses in only $10 \%$. Time from ovulation to next menses ranged from 7 to 19 days (days 10 to 22 of the menstrual cycle). Thus, the fertile window can occur much earlier or later in the cycle than clinical guidelines suggest. On average, at least $10 \%$ of women with regular cycles were in their fertile window on any given day of their cycle between days 6 and 21 (fig 2). The timing of the fertile window is even less predictable for women with less regular cycles, which includes adolescents and women in their perimenopause. ${ }^{17}$

Regarding the second assumption, the evidence for fertile days after ovulation comes from studies using crude measures of ovulation (for example, basal body temperature). With more precise measures, the fertile window does not seem to extend beyond the day of

\section{What is already known on this topic}

According to clinical guidelines, the average woman is potentially fertile between days 10 and 17 of her menstrual cycle

This assumes that ovulation occurs exactly 14 days before the onset of the next menses, and that the fertile window extends before and after ovulation; however, these assumptions are based on outdated information

\section{What this study adds}

The timing of the fertile window is highly variable, even among women who regard their menstrual cycles as regular

More than $70 \%$ of women are in their fertile window before day 10 or after day 17 of their menstrual cycle

There are few days of the menstrual cycle during which some women are not potentially fertile 
ovulation. ${ }^{12}$ It follows that women reach their fertile days earlier in the cycle than suggested by current guidelines. For example, women with regular 28 day cycles are most likely to be potentially fertile on days 8-15 of their menstrual cycle (fig 3).

\section{Advice to couples}

Figure 1 may be useful for couples who wish to time their intercourse to occur during the woman's fertile window. This approach can be improved by taking into account the regularity and usual length of the woman's cycle (figs 2 and 3). Because we excluded couples with known infertility problems, our data do not necessarily apply to couples having trouble conceiving. Any couple wishing to have a baby can easily avoid the uncertainty of predicting fertile days by engaging in intercourse two or three times a week.

Abstinence on specific days of the menstrual cycle remains a method of family planning for many couples worldwide. ${ }^{18}$ Women should be aware that no calendar method is completely effective. Our data suggest there are few days in the menstrual cycle during which some women are not potentially capable of becoming pregnant-including even the cycle day on which they may expect their next menses to begin.

Reverend B Maurice Ritchie translated the article by Pryll. Dr D Robert McConnaughey processed the data and provided the graphs. Joy Pierce supervised the field study. Dr Clarice Weinberg was a coinvestigator on the original study and offered suggestions at many stages. Drs Curtis Eshelman, Ruth Little, Dale Sandler, and Amy Sayle provided helpful comments on earlier drafts of the manuscript. We thank the women who participated. More details from the analysis are available on http:// dir.niehs.nih.gov/direb/supplem/home.

Contributors: AJW designed and directed the original study, conceived the data analysis, interpreted the results, and drafted the manuscript; he will act as guarantor. DD developed the statistical models, conducted the analysis, and helped interpret the results and compose the manuscript. DDB codirected the study, managed the steroid analyses, and helped interpret the results and compose the manuscript.
Funding: This project was conducted as part of the intramural research programme of the National Institute of Environmental Health Sciences, National Institutes of Health.

Competing interests: None declared.

1 Wilcox AJ, Weinberg CR, Baird DD. Timing of sexual intercourse in relation to ovulation: effects on the probability of conception, survival of the pregnancy and sex of the baby. N Engl J Med 1995;333:517-21.

2 Wilcox AJ, Weinberg CR, Baird DD. Post-ovulatory ageing of the human oocyte and embryo failure. Hum Reprod 1998;13:394-7.

3 Dunson DB, Baird DD, Wilcox AJ, Weinberg CR. Day-specific probabilities of clinical pregnancy based on two studies with imperfect measures of ovulation. Hum Reprod 1999;14:1835-9.

4 Wilcox AJ, Weinberg CR, O'Connor JF, Baird DD, Schlatterer JP, Canfield $\mathrm{RE}$, et al. Incidence of early loss of pregnancy. $N$ Engl J Med 1988;319:189-94.

5 Wilcox AJ, Weinberg CR, Wehmann RE, Armstrong EG, Canfield RF Nisula BC. Measuring early pregnancy loss: laboratory and field methods. Fertil Steril 1985;44:366-74.

6 Royston JP. Basal body temperature, ovulation and the risk of conception with special reference to the lifetimes of sperm and egg. Biometrics 1982;38:397-406.

7 Baird DD, Weinberg CR, Wilcox AJ, McConnaughey DR, Musey PI. Using the ratio of urinary estrogen and progesterone metabolites to estimate day of ovulation. Stat Med 1991;10:255-66

8 Guida M, Tommaselli GA, Palomba S, Pellicano M, Moccia G, Di Carlo C, et al. Efficacy of methods for determining ovulation in a natural family planning program. Fert Steril 1999;72:900-4

9 Dunson DB, Weinberg CR, Baird DD, Kesner JS, Wilcox AJ. Assessing human fertility using several markers of ovulation. Stat Med 2000 (in press)

10 Baird DD, McConnaughey DR, Weinberg CR, Musey PI, Collins DC, Kesner JS, et al. Application of a method for estimating day of ovulation using urinary estrogen and progesterone metabolites. Epidemiolog 1995;6:547-50.

11 Arévalo M, Sinai I, Jennings V. A fixed formula to define the fertile window of the menstrual cycle as the basis of a simple method of natural family planning. Contraception 2000;60:357-60.

12 Baird DD, Weinberg CR, Zhou H, Kamel F, McConnaughey DR, Kesne JS, et al. Preimplantation urinary hormone profiles and the probability of conception in healthy women. Fertil Steril 1999;71:40-9.

13 Pryll W. Kohabitationstermin und kindsgeschlecht. Muenchener Medizinische Wochenschrift. 1916;45:1579-82.

14 Technical Guidance/Competence Working Group. Family planning methods: new guidance. Popul Rep 1996;series J(44):14.

15 Beckmann CRB, Ling FW, Hebert WNP, Laube DW, Smith RP, Barzansky BM. Obstetrics and gynecology. Baltimore: Williams and Wilkins, 1998.

16 Lenton EA, Landgren B-M, Sexton L. Normal variation in the length of the luteal phase of the menstrual cycle: identification of the short luteal phase. Br J Obstet Gynaecol 1984;91:685-9.

17 Treloar AE, Boynton RE, Behn BG, Brown BW. Variation of the human menstrual cycle through reproductive life. Int J Fertil 1967;12:77-126.

18 Lamprecht VM, Grummer-Strawn L. Development of new formulas to identify the fertile time of the menstrual cycle. Contraception 1996;54:339-43

(Accepted 30 August 2000)

\title{
Cross sectional study of differences in coronary artery calcification by socioeconomic status
}

\author{
Helen M Colhoun, Michael B Rubens, S Richard Underwood, John H Fuller
}

Department of Epidemiology and Public Health, Royal Free and University College Medical School, University College London, London

WC1E 6BT

Helen M Colhoun senior lecturer

John H Fuller professor

continued over

BMJ 2000;321:1262-3
The relative contribution of socioeconomic differences in risk factors in adulthood versus earlier life to the social class gradient in coronary heart disease is controversial. ${ }^{1}$ Socioeconomic position in childhood was a strong predictor of stroke and cancer mortality in the Boyd Orr cohort but it had only a weak association with mortality from coronary heart disease. ${ }^{2}$ Furthermore, there is no social class gradient in intermediate vascular outcomes such as arterial distensibility in children. ${ }^{3}$ We examined whether there is a social class difference in coronary heart disease in adults in early mid-life by using a subclinical measure of coronary artery disease-coronary artery calcification.

\section{Methods and results}

We looked at the prevalence of coronary artery calcification in 149 men and women aged 30-40 (mean (SD) age
36 (2.5)) in relation to socioeconomic status. Participants were randomly sampled from the lists of patients from two general practices in London. Participants were included regardless of their cardiovascular history, although none had a history of coronary heart disease. The participants had formed the comparison group for a larger study that included type 1 diabetic patients. ${ }^{4}$ Two measures of socioeconomic status were used: current social class by own occupation using the registrar general's classification and whether they were in full time education at age 19. Fasting lipids were measured. We used electron beam computed tomography to quantify coronary artery calcification, a method that has been validated as a measure of coronary plaque volume. ${ }^{5}$ The odds of having any detectable calcification associated with social class were examined by using logistic regression, adjusting for covariates. These models were 